\title{
Psychological outcomes of different treatment policies in women with early breast cancer outside a clinical trial
}

\author{
L J Fallowfield, A Hall, G P Maguire, M Baum
}

\begin{abstract}
Objectives-To assess outside a clinical trial the psychological outcome of different treatment policies in women with early breast cancer who underwent either mastectomy or breast conservation surgery depending on the surgeon's opinion or the patient's choice. To determine whether the extent of psychiatric morbidity reported in women who underwent breast conservation surgery was associated with their participation in a randomised clinical trial.
\end{abstract}

Design-Prospective, multicentre study capitalising on individual and motivational differences among patients and the different management policies among surgeons for treating patients with early breast cancer.

Setting-12 District general hospitals, three London teaching hospitals, and four private hospitals.

Patients - 269 Women under 75 with a probable diagnosis of stage I or II breast cancer who were referred to 22 different surgeons.

Interventions-Surgery and radiotherapy or adjuvant chemotherapy, or both, depending on the individual surgeon's stated preferences for managing early breast cancer.

Main outcome measures-Anxiety and depression as assessed by standard methods two weeks, three months, and 12 months after surgery.

Results-Of the 269 women, 31 were treated by surgeons who favoured mastectomy, 120 by surgeons who favoured breast conservation, and 118 by surgeons who offered a choice of treatment. Sixty two of the women treated by surgeons who offered a choice were eligible to choose their surgery, and 43 of these chose breast conserving surgery. The incidences of anxiety, depression, and sexual dysfunction were high in all treatment groups. There were no significant differences in the incidences of anxiety and depression between women who underwent mastectomy and those who underwent lumpectomy. A significant effect of surgeon type on the incidence of depression was observed, with patients treated by surgeons who offered a choice showing less depression than those treated by other surgeons $(p=0 \cdot 06)$. There was no significant difference in psychiatric morbidity between women treated by surgeons who offered a choice who were eligible to choose their treatment and those in the same group who were not able to choose. Most of the women (159/244) gave fear of cancer as their primary fear rather than fear of losing a breast. The overall incidences of psychiatric morbidity in women who underwent mastectomy and those who underwent lumpectomy were similar to those found in the Cancer Research Campaign breast conservation study. (At 12 months $28 \%$ of women who underwent mastectomy in the present study were anxious compared with $26 \%$ in the earlier study, and $27 \%$ of women in the present study who underwent lumpectomy were anxious compared with $31 \%$ in the earlier study. In both the present and earlier study $21 \%$ of women who underwent mastectomy were depressed, and $19 \%$ of women who underwent lumpectomy in the present study were depressed compared with $27 \%$ in the earlier study.)

Conclusions-There is still no evidence that women with early breast cancer who undergo breast conservation surgery have less psychiatric morbidity after treatment than those who undergo mastectomy. Women who surrender autonomy for decision making by agreeing to participate in randomised clinical trials do not experience any different psychological, sexual, or social problems from those women who are treated for breast cancer outside a clinical trial.

\section{Introduction}

There have been numerous reports in medical journals 1 and the lay press ${ }^{23}$ of the psychological trauma produced by the diagnosis and treatment of breast cancer. It was hoped that breast conserving techniques would reduce psychiatric morbidity and sexual dysfunction, but these predictions have not been confirmed. At least 13 studies have compared the psychological impact of mastectomy with that of lumpectomy..$^{4-16}$ None of those studies in which psychiatric morbidity was adequately assessed showed any advantage to women who underwent breast conservation surgery. The small numbers of patients studied, however, meant that differences in psychiatric morbidity between treatment groups would have had to be very large to attain significance. In general, most studies reported a reduction in problems relating to body image in women who did not lose a breast, although one of the studies, which was reported by us, suggested that this advantage was offset by greater fears of cancer and of its possible recurrence. ${ }^{10}$

Our findings in this randomised trial, in which women were interviewed retrospectively, were criticised because the number of patients was small (101) and the assessments were retrospective. In addition, several authors suggested that randomised allocation to treatment after informed consent produced bias or was responsible for the psychosexual problems found. ${ }^{17}$ They argued that women with a greater sense of autonomy, who might cope better psychologically, would not accept randomisation; furthermore, such women would adapt more readily to their preferred treatment. ${ }^{18}$ Yet there is no firm evidence that all women wish to choose their treatment and that such choice in itself would reduce psychiatric morbidity. The four published studies that suggest that choice promotes psychological wellbeing are inconclusive because of methodological flaws, such as
Correspondence to:

BrMed $\mathcal{F} 1990 ; 301: 575-80$ 
short term follow up in small samples of women and incomplete reporting of data. ${ }^{721417}$

We conducted a prospective study of the psychological adjustment in a large sample of women by using validated assessment measures with a lengthier follow up than had been evident in earlier reports. Furthermore, we thought that the psychological impact of women's knowledge or ignorance that they were in a clinical trial had received wide publicity but little systematic study ${ }^{19-21}$; thus we conducted this pragmatic study also to address the major criticisms made of our previous work.

\section{Subjects and methods}

Surgeons who had participated in the Cancer Research Campaign breast conservation study and other surgeons whom we knew were invited to join the study. Those who accepted were encouraged to recruit other colleagues working within their health districts to participate. Twenty two surgeons agreed to participate. All of them were asked to state their primary surgical policy for treating patients with early breast cancer. Over about 18 months 269 women treated for early breast cancer at 19 different hospitals in 10 towns or cities in the south of England were registered by their referring surgeon with the study coordinator at the Cancer Research Campaign clinical trials centre in London. All of the women were under 75 and had a probable diagnosis of stage I or II breast cancer - that is, tumours of $\leqslant 5 \mathrm{~cm}$ diameter with or without palpable nodes and no evidence of distant metastases. These were the same diagnostic criteria as those used in the breast conservation study.

\section{TREATMENT}

The treatment offered to a patient depended on the surgical policy of her surgeon. Table I shows the three different surgeon "types" included and the numbers of women who underwent mastectomy or lumpectomy. We asked the surgeons how many women they had treated during the recruitment period to ensure that we had seen a representative sample. All except eight of the women who underwent breast conservation procedures also received radiotherapy. Adjuvant cytotoxic chemotherapy was given to $20(7 \%)$ of the 269 women. Most of the postmenopausal women (155 of $182 ; 85 \%)$, irrespective of surgical treatment, received adjuvant tamoxifen.

\section{METHOD}

On admission to hospital those women eligible for inclusion were given a letter inviting them to participate in the project, together with a consent form and three self assessment questionnaires to be completed preoperatively. Psychiatric morbidity, sexual functioning, and social adjustment were assessed using the same methods as in the breast conservation study. ${ }^{10}$

Self assessment questionnaires - The hospital anxiety and depression scale, ${ }^{22}$ Rotterdam symptom checklist, ${ }^{23}$ and Spielberger state/trait anxiety inventory ${ }^{24}$ were given to the patients preoperatively and at two weeks, three months, and 12 months postoperatively.

Semistructured psychiatric interviews - A shortened version of the present state examination ${ }^{25}$ was conducted by a trained interviewer about two weeks, three months, and 12 months postoperatively. Interviews took place in patients' homes to permit a more intimate discussion than is usually possible in busy hospitals. At the first home interview relevant social information (such as marital and occupational state and social support available) was collected, together with details as to how the breast lump was discovered, the woman's initial reactions to this discovery, and her recall of the way in which the diagnosis and treatment decisions were discussed. We asked women whether or not they felt that they had been offered a choice of treatment, how adequate the information given had been, and whether their primary fear on hearing the diagnosis was about possible breast loss or the fact of having cancer, or both. Interviews were tape recorded to permit tests of rate-rerate and interrater reliability.

At registration the surgeons indicated how they had decided on treatment (that is, on the basis of the patient's preference, the surgeon's preference, or for technical reasons). The three surgeons who offered choice of treatment unless technical reasons prevented this supplied us with tape recordings of about half of their consultations. This enabled us to make an objective assessment as to how decision making was facilitated. Moreover, we were able to compare the surgeon's perception and the woman's perception of this consultation against a transcript of the tape recording. Independent ratings of the surgeons' tapes showed $100 \%$ concordance with the patients' accounts of how treatment decisions were determined. Finally, an audit of all 269 patients' hospital notes was carried out to establish staging of the disease and to ensure that the recommended or self determined treatment

TABLE I-Three different surgeon types according to their primary surgical policy and numbers of their patients $(n=269)$ who underwent mastectomy or lumpectomy

\begin{tabular}{lccc}
\hline Treatment & $\begin{array}{c}\text { Surgeons who } \\
\text { favoured } \\
\text { mastectomy } \\
(\mathbf{n}=30)\end{array}$ & $\begin{array}{c}\text { Surgeons who } \\
\text { favoured } \\
\text { breast conservation } \\
(\mathbf{n}=121)\end{array}$ & $\begin{array}{c}\text { Surgeons who } \\
\text { offered } \\
\text { a choice } \\
(\mathbf{n}=118)\end{array}$ \\
\hline Mastectomy & 24 & 60 & 70 \\
Lumpectomy & 6 & 61 & 48 \\
\hline
\end{tabular}

TABLE II - Number (percentage) of women who underwent mastectomy or lumpectomy according to their demographic characteristics

\begin{tabular}{lcc}
\hline & $\begin{array}{c}\text { Women who underwent } \\
\text { mastectomy } \\
(\mathrm{n}=154)\end{array}$ & $\begin{array}{c}\text { Women who underwent } \\
\text { lumpectomy } \\
(\mathrm{n}=115)\end{array}$ \\
\hline $\begin{array}{l}\text { Mean }(\mathrm{SD} ; \text { range) age in } \\
\text { years }\end{array}$ & $56(11 ; 26-74)$ & $56(11 ; 20-75)$ \\
Marital state: & & \\
$\quad$ Married or cohabiting & $113(73)$ & $77(67)$ \\
Single or widowed & $32(21)$ & $25(22)$ \\
$\quad$ Separated or divorced & $9(6)$ & $13(11)$ \\
Social class ${ }^{\star}$ I & $8(5)$ & $10(9)$ \\
I & $46(30)$ & $39(34)$ \\
II & $23(15)$ & $28(24)$ \\
III non-manual & $53(34)$ & $28(24)$ \\
III manual & $20(13)$ & $9(8)$ \\
IV & $4(3)$ & $1(1)$ \\
V & & \\
\hline
\end{tabular}

${ }^{\star}$ By the Registrar General's classification of occupations (1980). Women were classified according to their husband's occupation if married or according to self if single.

TABLE III -Choice of treatment among women treated by surgeons who offered a choice and eligible to choose their own treatment $(n=62)$

\begin{tabular}{ccc}
\hline & \multicolumn{2}{c}{ Treatment choice } \\
\cline { 2 - 3 } Age group & Mastectomy & Lumpectomy \\
\hline $30-39$ & 1 & 4 \\
-49 & 4 & 14 \\
-59 & 6 & 12 \\
-69 & 5 & 10 \\
-75 & 3 & 3 \\
\hline Total & $19(31 \%)$ & $43(69 \%)$ \\
\hline
\end{tabular}

TABLE IV-Number of women experiencing anxiety during the first 12 months after surgery

\begin{tabular}{lcc}
\hline Time after surgery & $\begin{array}{c}\text { Women who underwent } \\
\text { mastectomy }\end{array}$ & $\begin{array}{c}\text { Women who underwent } \\
\text { lumpectomy }\end{array}$ \\
\hline Two weeks & $64 / 154(42 \%)$ & $42 / 115(37 \%)$ \\
Three months & $48 / 149(32 \%)$ & $34 / 110(31 \%)$ \\
12 Months & $39 / 140(28 \%)$ & $29 / 108(27 \%)$ \\
\hline
\end{tabular}


TABLE $\mathrm{V}-$ Anxiety and depression in women according to surgeon group and treatment

\begin{tabular}{|c|c|c|c|c|c|c|}
\hline & \multicolumn{2}{|c|}{$\begin{array}{l}\text { Surgeons who favoured } \\
\text { mastectomy }\end{array}$} & \multicolumn{2}{|c|}{$\begin{array}{l}\text { Surgeons who favoured } \\
\text { breast conservation }\end{array}$} & \multicolumn{2}{|c|}{$\begin{array}{l}\text { Surgeons who offered } \\
\text { a choice }\end{array}$} \\
\hline & Mastectomy & Lumpectomy & Mastectomy & Lumpectomy & Mastectomy & Lumpectomy \\
\hline \multicolumn{7}{|c|}{ Postoperatively } \\
\hline $\begin{array}{l}\text { Anxiety } \\
\text { Depression }\end{array}$ & $\begin{array}{r}14 / 24(58 \%) \\
9 / 24(38 \%)\end{array}$ & $\begin{array}{l}2 / 6(33 \%) \\
2 / 6(33 \%)\end{array}$ & $\begin{array}{l}27 / 60(45 \%) \\
19 / 60(32 \%)\end{array}$ & $\begin{array}{l}24 / 61(39 \%) \\
15 / 61(25 \%)\end{array}$ & $\begin{array}{l}23 / 70(33 \%) \\
16 / 70(23 \%)\end{array}$ & $\begin{array}{r}16 / 48(33 \%) \\
8 / 48(17 \%)\end{array}$ \\
\hline \multicolumn{7}{|c|}{ At three months ${ }^{\star}$} \\
\hline $\begin{array}{l}\text { Anxiety } \\
\text { Depression }\end{array}$ & $\begin{array}{l}10 / 23(43 \%) \\
10 / 23(43 \%)\end{array}$ & $\begin{array}{l}2 / 5(40 \%) \\
2 / 5(40 \%)\end{array}$ & $\begin{array}{l}19 / 59(32 \%) \\
16 / 59(27 \%)\end{array}$ & $\begin{array}{l}19 / 59(32 \%) \\
10 / 59(17 \%)\end{array}$ & $\begin{array}{l}19 / 67(28 \%) \\
14 / 67(21 \%)\end{array}$ & $\begin{array}{r}13 / 46(28 \%) \\
5 / 46(11 \%)\end{array}$ \\
\hline \multicolumn{7}{|c|}{ At 12 monthst } \\
\hline $\begin{array}{l}\text { Anxiety } \\
\text { Depression }\end{array}$ & $\begin{array}{l}9 / 21(43 \%) \\
5 / 21(24 \%)\end{array}$ & $\begin{array}{l}2 / 6(33 \%) \\
1 / 6(17 \%)\end{array}$ & $\begin{array}{l}17 / 55(31 \%) \\
14 / 55(25 \%)\end{array}$ & $\begin{array}{l}15 / 57(26 \%) \\
11 / 57(19 \%)\end{array}$ & $\begin{array}{l}13 / 64(20 \%) \\
11 / 64(17 \%)\end{array}$ & $\begin{array}{r}12 / 45(27 \%) \\
8 / 45(18 \%)\end{array}$ \\
\hline
\end{tabular}

«Two patients had died, six did not wish to be interviewed, and two could not be seen for practical reasons.

†A further eight patients had died, three did not wish to be interviewed, and two could not be seen for practical reasons.

had been carried out for the reasons stated on the registration form.

\section{STATISTICS}

The data on psychological outcome consisted of a series of measurements in individual patients. These were summarised for each patient by calculating a total weighted score that represented the estimated time for which a psychological state existed in the first year after surgery. This method of analysing serial measurements has been described. ${ }^{26}$ Univariate analyses were performed using Wilcoxon's rank sum and Kruskal Wallis tests. Multivariate analysis was undertaken using logistic regression by the biomedical programs data package. Results of logistic regression were summarised by calculating the odds ratios derived from the models obtained from the data package, factors being fitted in a forward stepwise fashion and including all factors that were significant to the $10 \%$ level. For the purposes of the logistic regression patients were defined as either suffering from the psychological state during the first year or not. Factors included in the analysis were surgeon type, whether or not patients had a choice, operation type, age, stage of cancer, and adjuvant treatment (tamoxifen, radiotherapy, and chemotherapy). Preoperative psychological variables used were the Spielberger state/trait anxiety inventory, the Rotterdam symptom checklist (item 18), and the hospital and anxiety and depression scale.

Analysing such a large number of variables may give rise to spuriously significant effects due to multiple comparisons. As the primary factors of interest were surgeon type and treatment given, these are the main results reported in this paper. More detailed analysis will be reported at a later date.

\section{Results}

ACCRUAL OF PATIENTS

Out of 299 women, $269(90 \%)$ agreed to participate. Although recruitment was good overall, we had difficulty in gaining access to many women seen by the surgeons who favoured mastectomy as the primary treatment. During the course of the study it seemed as though general practitioners were tending to refer women to surgeons known to offer both treatments rather than those committed only to mastectomy. Of 30 women treated by surgeons who favoured mastectomy, 24 underwent mastectomy and six underwent lumpectomy. Of the 121 women seen by surgeons who favoured breast conserving surgery whenever possible, 60 underwent mastectomy and 61 lumpectomy. Among the women treated by surgeons who offered the choice of treatment unless technical reasons prevented this, 70 women underwent mastectomy and 48 lumpectomy.
Very few women were lost to follow up: at 12 months 248 women were interviewed. Of the 21 women not seen, two were not interviewed because of practical difficulties, 10 women had died, and nine women had indicated that they did not wish to continue with the study. Interestingly, six of these nine women were very anxious or depressed, or both, and therefore the psychiatric morbidity we report is likely to be a slight underestimate.

\section{SOCIODEMOGRAPHIC CHARACTERISTICS}

Table II gives the sociodemographic characteristics of the sample. An equal percentage of women $(50 \%)$ in both higher (class I, II, and III non-manual) and lower (class III manual, IV, and V) socioeconomic groups underwent mastectomy. Of 115 women who underwent breast conservation, 77 belonged to the higher socioeconomic groups.

\section{TREATMENT CHOICE}

Of the patients of the surgeons who offered a choice of treatment 62 women were eligible to choose their surgery and 56 women had their treatment determined by the surgeon and radiotherapist based on technical considerations such as breast size or the size and position of the tumour relative to the nipple. Table III shows the treatment choices made according to the age of the women. Over two thirds (43 of 62 women) ( $95 \%$ confidence interval $57 \%$ to $81 \%$ ) chose breast conserving surgery. Therefore it is unlikely that the true proportion of women who would choose breast conservation would exceed $81 \%$. Nearly all of the women who chose mastectomy were over 50 . However, 25 of the 43 women $(58 \%)$ who chose lumpectomy were also over 50 . Of the 21 women aged between 60 and 75 years who were given choice of treatment, eight chose to have a mastectomy and 13 chose lumpectomy.

\section{RELIABILITY OF INTERVIEWS}

Checks of rate-rerate reliability at each time interval were performed on a random sample of $241(30 \%)$ of the tape recorded interviews. Any discrepancies were checked by an independent rater. Ratings showed little evidence of drift. Interrater reliability checks for each of the three interviewers were also performed on a further 81 of $269(10 \%)$ tapes and showed good overall concordance between interviewers. All reliability coefficients were found to be within satisfactory limits by using a weighted $x$ statistic. ${ }^{27}$

\section{PSYCHIATRIC MORBIDITY}

Anxiety by treatment group-Two weeks postoperatively the number of women experiencing anxiety was considerable (table IV), irrespective of the treatment given. Sixty four of $154(42 \%)$ women who underwent mastectomy and 42 of $115(37 \%)$ who underwent lumpectomy were anxious. Anxiety was still apparent at three months. Forty eight of 149 (32\%) women who underwent mastectomy and 34 of 110 (31\%) women who underwent lumpectomy were anxious. By 12 months the number of women with morbid anxiety had declined but was still high. Thirty nine of $140(28 \%)$ women who underwent mastectomy and 29 of $108(27 \%)$ who underwent lumpectomy were assessed as being anxious. No significant difference between the two treatments was found $(p=0 \cdot 21)$.

Anxiety by surgeon group - At each assessment anxiety ratings were high (table V). However, univariate analysis provided no firm suggestion of the effect of surgeon type $(p=0 \cdot 1)$. With multivariate analysis a significant effect of surgeon type was found $(p=0.01)$; the odds ratios for women treated by surgeons who favoured mastectomy, lumpectomy, and choice were $1.00,0.57$, and 0.22 respectively. These ratios indicate 
a decreasing incidence of anxiety across the three groups.

Depression by treatment group-Between $15 \%$ and $29 \%$ of women irrespective of treatment were found to be depressed at each assessment (table VI). Univariate analysis showed a suggestion of decreasing depression with time among the patients who underwent lumpectomy $(\mathrm{p}=0 \cdot 04)$. On multivariate analysis this effect was no longer present.

Depression by surgeon group-Univariate analysis suggested a significant effect of surgeon type $(p=0.03)$, with the patients of surgeons who favoured mastectomy showing more depression than those women treated by the surgeons who favoured lumpectomy. Those patients treated by surgeons who offered a choice showed less depression than patients in either of the other two groups (table V). With multivariate analysis this effect was still present $(p=0 \cdot 06)$. The odds ratios were $1.00,0.55$, and 0.30 for the three groups respectively.

Effect of choice-Fewer women treated by surgeons who offered a choice were rated as anxious or depressed, or both (table V) compared with other surgeons' patients. Table VII shows the effect of choice on psychiatric morbidity in this group irrespective of the treatment given. There were no significant differences between those women who had a real choice and those given no choice at any of the three assessments.

At 12 months 248 of our original sample were available for assessment. When the psychiatric morbidity in women who had a real choice at 12 months

TABLE VI-Depression in women according to treatment over first 12 months after surgery

\begin{tabular}{lcc}
\hline Time after surgery & $\begin{array}{c}\text { Women who underwent } \\
\text { mastectomy }\end{array}$ & $\begin{array}{c}\text { Women who underwent } \\
\text { lumpectomy }\end{array}$ \\
\hline Postoperatively & $44 / 154(29 \%)$ & $25 / 115(22 \%)$ \\
Three months & $40 / 149(27 \%)$ & $17 / 110(15 \%)$ \\
12 Months & $30 / 140(21 \%)$ & $20 / 108(19 \%)$ \\
\hline
\end{tabular}

TABLE VII-Effect of choice on psychiatric morbidity among women treated by surgeons who offered a choice

\begin{tabular}{lcc}
\hline & Women with a real choice & Women without a real choice \\
\hline \multicolumn{3}{c}{ Postoperatively } \\
Anxiety & $21 / 62(34 \%)$ & $18 / 56(32 \%)$ \\
Depression & $16 / 62(26 \%)$ & $8 / 56(14 \%)$ \\
& At three months \\
Anxiety & $18 / 58(31 \%)$ & $14 / 55(25 \%)$ \\
Depression & $8 / 58(14 \%)$ & $11 / 55(20 \%)$ \\
& At 12 months & \\
Anxiety & $14 / 57(25 \%)$ & $11 / 52(21 \%)$ \\
Depression & $10 / 57(18 \%)$ & $9 / 52(17 \%)$ \\
\hline
\end{tabular}

TABLE VIII-Effect of choice on psychiatric morbidity at 12 months among women treated by all three surgeon types according to treatment Women with a real choice Women without a real choice

\begin{tabular}{lrrrrr} 
& \multicolumn{2}{c}{$\begin{array}{c}\text { Women with a real choice } \\
(\mathrm{n}=57)\end{array}$} & & $\begin{array}{c}\text { Women without a real choice } \\
(\mathrm{n}=191)\end{array}$ \\
\cline { 2 - 3 } \cline { 5 - 6 } & Mastectomy & Lumpectomy & & Mastectomy & Lumpectomy \\
\hline Anxiety & $3 / 16(19 \%)$ & $11 / 41(27 \%)$ & & $36 / 124(29 \%)$ & $18 / 67(27 \%)$ \\
Depression & $2 / 16(13 \%)$ & $8 / 41(20 \%)$ & & $28 / 124(23 \%)$ & $12 / 67(18 \%)$
\end{tabular}

TABLE IX - Primary concern expressed by women on hearing diagnosis according to treatment

\begin{tabular}{lcc}
\hline Primary fear & $\begin{array}{c}\text { Women who underwent } \\
\text { mastectomy } \\
\left(\mathbf{n}=146^{\star}\right)\end{array}$ & $\begin{array}{c}\text { Women who underwent } \\
\text { lumpectomy } \\
(\mathrm{n}=98 \dagger)\end{array}$ \\
\hline Cancer & $89(61 \%)$ & $70(71 \%)$ \\
Breast loss & $18(12 \%)$ & $14(14 \%)$ \\
Both & $39(27 \%)$ & $14(14 \%)$
\end{tabular}

^Eight women did not express either concern.

†Seventeen women did not express either concern. was compared with that in women who were treated by all three types of surgeons and who did not have a real choice there are no significant advantages to the women with a choice (table VIII), although those women who chose mastectomy seemed less anxious and depressed than those who underwent this treatment but had no choice.

Follow up data for two and three years after treatment are still being collected, so it is too early to make any firm statements about the putative benefits of offering patients a choice of treatment.

Factors affecting choice-At interview women who chose mastectomy had firmer convictions about the benefits of mastectomy in terms of removing all of the cancer. Most of the women gave fear of cancer as their worst thought rather than fear of breast loss, irrespective of the eventual surgical treatment they received (table IX). Only 32 of $269(12 \%)$ women, 18 of whom underwent mastectomy and 14 of whom underwent lumpectomy, thought that the fear of losing a breast was worse than that of having cancer.

Assumptions that elderly women do not mind losing a breast are not supported by our data: 13 of 21 women over 60 who were able to choose their treatment opted for lumpectomy (table III).

\section{COMPARISON WITH BREAST CONSERVATION STUDY}

Anxiety-Almost 12 months after operation 14 of the $53(26 \%)$ women who underwent mastectomy after randomisation in the breast conservation study experienced an anxiety state compared with 39 of 140 $(28 \%)$ in the current study. Fifteen of 48 (31\%) women after lumpectomy in the randomised clinical trial were anxious compared with 29 of $108(27 \%)$ in the current study. Thus the incidence of anxiety was almost identical in both studies, irrespective of surgical treatment.

Depression-For women who underwent mastectomy the incidence of depressive illness was identical in both studies. Eleven out of 53 (21\%) women who underwent mastectomy after randomisation were depressed compared with 30 out of $140(21 \%)$ in the current study. Thirteen of $48(27 \%)$ women who underwent lumpectomy after randomisation were depressed compared with 20 out of 108 (19\%) in the current study. None of these differences were significant.

Sexual dysfunction-A single self report item on the Rotterdam symptom checklist assessed loss of sexual interest. Eighteen of the 48 (38\%) women with sexual partners who underwent mastectomy and 15 out of 39 (38\%) who underwent lumpectomy in the breast conservation trial reported a loss of sexual interest compared with 33 of $120(28 \%)$ and 30 of $100(30 \%)$ women in the current study. There was no significant difference between the two treatment groups or between the two studies, with well over a quarter of all women reporting sexual dysfunction.

Satisfaction with information given - The protocol for the breast conservation trial required that participating surgeons discussed treatment options with patients to determine whether they had any strong preference for one particular surgical procedure before randomisation. In addition, most ethical committees of the centres participating in the study demanded fully informed consent. Despite this emphasis on the giving of information 52 of $100(52 \%)$ of the women thought that they had received inadequate information Furthermore, those women who thought that they had been poorly informed were twice as likely to be depressed or anxious, or both, at 12 months compared with those who thought that they had been adequately informed. In the current study 54 of 152 (36\%) women who underwent mastectomy and 26 of $115(23 \%)$ women who underwent lumpectomy thought that the 
information given at the hospital was inadequate (data are missing for two patients).

An interesting finding, which again supports data from the breast conservation study, concerns the difference in the incidence of anxiety or depression, or both, at 12 months. There are complete data for 246 women (data are missing because of death or unavailability of patients). Of the 176 women who thought that they had been well informed, $46(26 \%)$ were assessed as anxious or depressed; but of those women who thought that they had been poorly informed 32 out of $70(46 \%)$ were anxious or depressed, or both ( $\mathrm{p}=0.005$ by $\chi^{2}$ test). As the breast conservation study was retrospective it was not possible to determine the direction of causality: Were those patients in whom anxiety was found anxious because they had been poorly informed or was their perception of the information given to them affected by the fact that they were anxious to start with?

In the current prospective study women were given preoperatively the Spielberger state/trait anxiety inventory, a self report questionnaire used to identify those people in whom anxiety is a characteristic trait. ${ }^{24}$ The mean (SD) score for those who thought they had been inadequately informed was $39.9(11 \cdot 45)$, and for those who thought that they had been adequately informed it was $34.86(9.95)(\mathrm{p}<0.0004$, Student's $t$ test). The mean (SD) score in a group of women aged 50-69 without breast cancer was $31 \cdot 79(7 \cdot 78) .^{24}$

\section{Discussion}

There is still no evidence that breast conserving procedures ensure protection from psychosocial and sexual dysfunction. Just as there is no standard surgical treatment for breast cancer that conveys an obvious benefit to women in terms of overall survival, there is no standard procedure guaranteed to promote psychological survival. Dogmatic assertions that breast conserving treatment preserves body image and therefore psychological wellbeing are tautologous, simplistic, and based on weak data from methodologically unsound studies. Concentrating on altered body image may tell us very little; what is more important is the impact that these concerns may exert on psychological functioning.

Fear of cancer and of its possible recurrence seems to be a compelling factor in determining a woman's preference for treatment. The effects of offering women a choice of treatment whenever possible do not seem to be the only variables that might have some impact on psychiatric morbidity; our results suggest that surgeon type and the manner in which decisions on treatment are made may also influence outcome. The women who were treated by surgeons who offered a choice seemed to have less psychiatric morbidity than other surgeons' patients, whether or not they were able to exercise real choice. Unfortunately the numbers of women able to choose their treatment in this study were small, and more research is needed in a large sample of women with appropriate follow up.

Until we have analysed data from assessments at two and three years we are unable to draw any firm conclusions or make any helpful suggestions to clinicians concerning the putative benefit of allowing women more autonomy in the decision making process. One potential difficulty with giving patients responsibility for the treatment decision could be that they then assume responsibility for the outcome of the treatment. If things go well then there may be no problem. If breast cancer recurs locally, however, as it does in about $20 \%$ of those women who undergo breast conserving procedures, ${ }^{28}$ then women may well experience emotional distress at having chosen "wrongly." There are reports of the psychologically damaging impact of patients assuming responsibility for treatment outcomes that are unsuccessful. ${ }^{29}$ Evidence from other specialties of medicine suggests that certain adaptive cognitive behaviours are developed to relieve cognitive dissonance and may protect patients from experiencing too much self recrimination after "failed" treatment decisions. ${ }^{30}$ What many women want, rather than the ultimate decision on surgical treatment, is more adequate information as to why one treatment is recommended over another. ${ }^{31}$

Assertions that the high rates of psychiatric morbidity in the Cancer Research Campaign breast conservation study were an artefact of informed consent are not supported by data from the current study. Furthermore, the lack of any substantial difference in psychiatric morbidity between those women who underwent mastectomy and those who underwent breast conserving surgery cannot be due to the equalisation of important contextual factors during randomisation. It has been argued that in any randomised study of surgery for breast cancer in which treatment is allocated after fully informed consent is obtained there would be several women in each group with a strong preference for either the allocated treatment or the alternative. ${ }^{32}$ Those receiving their preferred treatment would do better as motivational factors would ensure a better outcome, and vice versa; hence the finding of no difference in psychiatric morbidity. But this argument would apply only if equal numbers of women opted for each treatment. Our data on those women who were able to choose suggested that one third preferred mastectomy and two thirds preferred lumpectomy. Thus, far from predicting a finding of no difference, there should have been an obvious advantage to the women who underwent lumpectomy.

Our results suggest that the way in which the surgeon conducts the consultation during which the bad news that cancer is present is given may have important consequences for long term adjustment. Women in whom anxiety is a characteristic trait are more likely to perceive the information as inadequate and be clinically anxious or depressed, or both, at 12 months. If these anxiety prone women can be identified at an early stage by the use of screening systems such as the Spielberger state/trait anxiety inventory before seeing the surgeon then intervention could be possible. These women may well need a close companion to accompany them during the consultation. ${ }^{33}$ They also might benefit from taking home an audio tape recording of the interview. ${ }^{34}$ Finally, they may require more help in discussing the information with a properly trained oncology counsellor or breast nurse specialist. ${ }^{33} 35$

Ethical dilemmas abound in the field of breast cancer research. Some of the most vociferous proponents of the controversies jeopardise their arguments by ignoring the more fundamental ethical dilemma of providing care in the absence of any research evidence. Consumer choice without scientific knowledge of likely outcomes is meaningless. Opinions vary from "concern for the interests of the subject must always prevail over the interests of science and society" ${ }^{36}$ to beliefs that it is unethical not to conduct a controlled trial when clinicians recognise their uncertainty. ${ }^{37}$

The worries that fully informing women of this uncertainty at a time when they are already experiencing emotional distress about having a life threatening disease are real. Indeed, problems with informed consent have been one of the most commonly expressed reasons for not entering eligible women into trials of breast cancer surgery. ${ }^{2138}$ There is no evidence from our work, however, to suggest that participation in a randomised clinical trial of surgery for 
early breast cancer in itself produces psychiatric morbidity.

We thank the Cancer Research Council for financial support. We also thank Ruth Sutton and Stella Khenia for their help with the preparation of data for analysis, Roger A'Hern for statistical advice, and Philippa Male for help with interviewing and rerating tape recordings. Finally, we thank all the surgeons and their patients for participating in the study.

1 Bard M, Sutherland AM. Psychological impact of cancer and its treatment. Cancer 1955;8:656-72.

2 Inglis B. The unkindest cut. Guardian 1981 Sept 26:9.

3 Faulder C. Unheard victims of breast cancer. Independent 1986 Oct 7:4

4 Sanger CK, Reznikoff M. A comparison of the psychological effects of breast-saving procedures with the modified radical mastectomy. Cancer 1981;48:2341-6

5 Schain W, Edwards BK, Gorrell CR, et al. Psychosocial and physical outcomes of primary breast cancer therapy: mastectomy vs excisional biopsy and of primary breast cancer therapy: mastectomy vs excisional biop
irradiation. Breast Cancer Research and Treatment 1983;3:377-82.

6 Steinberg MD, Juliano MS, Wise L. Psychological outcome of lumpectomy versus mastectomy in the treatment of breast cancer. Am I Psychiatry 1985:142:34-9.

7 Ashcroft JJ, Leinster SJ, Slade PD. Breast cancer-patient choice of treatment: preliminary communication. $\mathcal{F} R$ Soc Med 1985;78:43-6.

8 De Haes JCJM, van Oostrom MA, Welvaart $K$. The effect of radical and conserving surgery on the quality of life of early breast cancer patients. Eur F Surg Oncol 1986;12:337-42.

9 Bartelink H, van Dam F, van Dongen J. Psychological effects of breast conserving therapy in comparison with radical mastectomy. Int $f$ Radiat Oncol Biol Phys 1985;11:381-5.

10 Fallowfield LJ, Baum M, Maguire GP. Effects of breast conservation on psychological morbidity associated with diagnosis and treatment of early breast cancer. BrMed f 1986:293:1331-4.

11 Lasry JCM, Margolese RG, Poisson R, et al. Depression and body image following mastectomy and lumpectomy. $f$ Chronic Dis 1987;40:529-34.

Wolberg WH, Tanner MA, Romsaas EP, et al. Factors influencing options in primary breast cancer treatment. $\mathcal{F}$ Clin Oncol 1987;5:68-74.

13 Kemeny MM, Wellisch DK, Schains WS. Psychosocial outcome in a randomised surgical trial for treatment of primary breast cancer. Cancer 1988;62:1231-7.

14 Morris J, Royle GT, Taylor I. Changes in the surgical management of early breast cancer in England. $\mathcal{F} R$ Soc Med 1989;82:12-4.

15 Meyer L, Aspergren K. Long term psychological-sequelae of mastectomy and breast conserving treatment for breast cancer. Acta Oncol 1989;28:13-8.

16 Maunsell E, Brisson J, Deschenes L. Psychological distress after initial treatment for breast cancer: a comparison of partial and total mastectomy. f Clin Epidemiol 1989;42:765-71.
17 Wilson RG, Hart A, Dawes PJDK. Mastectomy or conservation: the patient's choice. Br Med J 1988;297:1167-72.

8 Milner PC, Nicholl JP. Effects of breast conservation on psychological morbidity. BrMed f 1986:293:1568.

9 Sims RJ, Tattersall MHN, Coates AS, et al. Randomised comparison of procedures for obtaining informed consent in clinical trials of treatment for cancer. Br Med f 1980;293:1065-8.

20 King J, Nicholson R. Informed consent. Institute of Medical Ethics Bulletin 1986;3(suppl).

21 Baum M, Zilkha K, Houghton J. Ethics of clinical research: lessons for the future. BrMed f 1989;299:251-3.

22 Zigmund AS, Snaith RP. The hospital anxiety and depression scale. Acta Psychiatr Scand 1983;67:361-70.

23 De Haes JCJM, Pruyn JFA, Knippenberg FCE. Klachtenlijst voor kankerpatienten. Eerste ervaringen. Nederlands. Tijdschrift voor de Psychologie 1983;38:403-22.

44 Spielberger CD, Gorsuch RL, Lusherie RE. STAI manual (Form Y). Palo Alto, California: Consulting Psychologists Press, 1983.

25 Wing JK, Cooper JE, Sartorius N. Measurement and classification of psychiatric symptoms. Cambridge: Cambridge University Press, 1974

26 Matthews JNS, Altman DG, Campbell MJ, et al. Analysis of serial measurements in medical research. Br Med f 1990;300:230-5.

27 Cohen J. A coefficient of agreement for nominal scales. Educational and Psychological Measurement 1960;20:37-46.

28 Locker AP, Ellis IO, Morgan DAL, et al. Factors influencing local recurrence after excision and radiotherapy for primary breast cancer. Br $\mathcal{J}$ Surg $1989 \cdot 76 \cdot 890-4$

29 Clements CD, Sider RC. Medical ethics' assault upon medical values. JAMA 1983;250:2011-5.

30 Wagener JJ, Taylor SE. What else could I have done? Patients' responses to failed treatment decisions. Health Psychol 1986;5:481-96.

31 Sutherland HJ, Llewellyn-Thomas HA, Lockwood GA, et al. Cancer patients: their desire for information and participation in treatment decisions. f R Soc Med 1989;82:260-7.

32 Brewin CR, Bradley C. Patient preferences and randomised clinical trials. BrMed f 1989;299:313-5.

33 Fallowfield LJ, Baum M. Psychological welfare of patients with breast cancer. f $R$ Soc Med 1989;82:4-5.

34 Hogbin B, Fallowfield LJ. Getting it taped: the "bad news" consultation with cancer patients. Br f Hosp Med 1989;41:330-3.

35 Fallowfield LJ. Counselling for patients with cancer. Br Med 7 1988;297. 727-8.

36 Levine RJ. Referral of patients with cancer for participation in randomised clinical trials: ethical considerations. $C A$ 1986;36:95-9.

37 Bradford Hill A. Statistical methods in clinical and preventative medicine. New York: Oxford University Press, 1962.

38 Taylor KM, Margolese RG, Soskolne CL. Physicians' reasons for not entering eligible patients into a randomised clinical trial of surgery for breast cancer. NEngl f Med 1984;310:1363-7.

\title{
Long term reduction in sodium balance: possible additional mechanism whereby nifedipine lowers blood pressure
}

\author{
Joe B Pevahouse, Nirmala D Markandu, Francesco P Cappuccio, Martin G Buckley, \\ Giuseppe A Sagnella, Graham A MacGregor
}

Abstract

Objective-To assess the changes in sodium excretion and sodium balance after withdrawal of long term nifedipine.

Design-Single blind, placebo controlled study in patients receiving fixed sodium and potassium intakes.

Setting-Blood pressure unit of a teaching hospital in south London.

Patients-Eight patients with mild to moderate uncomplicated essential hypertension who had been taking nifedipine $20 \mathrm{mg}$ twice daily for at least six weeks.

Interventions-Withdrawal of nifedipine and replacement with matching placebo for one week.

Main outcome measures-Urinary sodium excretion and cumulative sodium balance, body weight, plasma atrial natriuretic peptide concentrations, plasma renin activity and aldosterone concentrations, and blood pressure.

Results-During nifedipine withdrawal there was a significant reduction in urinary sodium excretion (day 1: $-62.7 \mathrm{mmol} / 24 \mathrm{~h} ; 95 \%$ confidence interval -90.3 to -35.0$)$ and each patient retained a mean of 146 (SEM 26) mmol sodium over the week of replacement with placebo. Body weight and plasma atrial natriuretic peptide concentrations increased during the placebo period and seemed to be associated with the amount of sodium retained. Systolic blood pressure rose from 157 (9) to 165 (9) $\mathrm{mm} \mathrm{Hg}(95 \%$ confidence interval of difference $-7 \cdot 1$ to $22 \cdot 1$ ) when nifedipine was replaced with matching placebo, and the rise seemed to be related to the amount of sodium that was retained.

Conclusions-Nifedipine causes a long term reduction in sodium balance in patients with essential hypertension. This long term effect may contribute to the mechanism whereby nifedipine lowers blood pressure.

\section{Introduction}

Nifedipine is now widely used for the treatment of both angina and hypertension. ${ }^{1}$ Its blood pressure lowering effect has been shown to be due to its inhibition of calcium induced contraction of arteriolar smooth muscle, which leads to peripheral vasodilatation. ${ }^{2}$ This effect on arteriolar smooth muscle has been shown to be greater the higher the blood pressure. ${ }^{3}$ An early intravenous study with nifedipine showed that it also caused a natriuresis and diuresis. ${ }^{4}$ Later studies confirmed that acutely nifedipine causes a loss of sodium, which is independent of haemodynamic changes, ${ }^{5.7}$ and one study detected a greater increase in

Correspondence to: 